\title{
The impact of nonmotor symptoms on quality of life in patients with Parkinson's disease in Taiwan
}

\author{
This article was published in the following Dove Press journal: \\ Neuropsychiatric Disease and Treatment \\ II November 2015 \\ Number of times this article has been viewed
}

\section{Weng-Ming Liu ${ }^{1,2}$ \\ Ru-Jen Lin' \\ Rwei-Ling $\mathrm{Yu}^{3}$ \\ Chun-Hwei Tai' \\ Chin-Hsien Lin' \\ Ruey-Meei Wu'}

'Department of Neurology, National Taiwan University Hospital, College of Medicine, National Taiwan University, Taipei, Taiwan; ${ }^{2}$ Department of Neurology, Buddhist Tzu Chi General Hospital, Hualien, Taiwan; ${ }^{3}$ Institute of Behavioral Medicine, College of Medicine, National Cheng Kung University, Tainan, Taiwan
Correspondence: Ruey-Meei Wu Department of Neurology, National Taiwan University Hospital, College of Medicine, National Taiwan University, 7 Chung Shan South Rd, Zhongzheng District, Taipei City 10002, Taiwan Tel +886223123456 extension 65337 Fax +886222 34I 8395 Email robinwu@ntu.edu.tw
Purpose: The nonmotor symptoms (NMS) of Parkinson's disease (PD) are important factors for quality of life (QoL). Few studies on NMS have been conducted in Asian PD patients. Additionally, effects of anti-PD drugs on risk of NMS are still controversial. We therefore conducted this hospital-based cross-sectional study to examine the clinical factors, including concomitant anti-PD medication use, on the occurrence of NMS and QoL in Taiwanese PD patients.

Patients and methods: PD patients who received long-term follow-up in the movement disorders clinics were enrolled and received NMS questionnaire (NMSQuest) and the 39-item Parkinson's Disease Questionnaire (PDQ-39). Spearman's rank correlation coefficient was checked for the correlation between clinical factors and NMSQT/PDQSI. Multiple linear regressions were applied to assess the influence of clinical factors on NMSQT/PDQSI.

Results: A total of 210 PD patients (mean age 66.1 \pm 9.86 years, Hoehn and Yahr stage 2.2 \pm 0.9 ) were included in this study. Up to $98 \%$ of patients reported at least one symptom of NMS. The most prevalent symptom was urinary complaints $(56 \%)$, followed by memory/apathy $(30 \%)$ and depression/anxiety (28\%). The correlation between NMSQT and PDQSI was strong $\left(r_{\mathrm{s}}=0.667\right)$, especially the item of depression/anxiety $\left(r_{\mathrm{s}}=0.607\right)$. The regression model for NMSQT indicated that disease duration and severity, but not pharmacological therapy, were major predictors of NMS.

Conclusion: Our data indicated a high prevalence rate of NMS in PD patients. Among symptoms of NMS, depression and anxiety had the greatest impact on QoL. Concomitant anti-PD medication use did not affect the occurrence of NMS and QoL.

Keywords: NMS, NMSQuest, NMS questionnaire, PD, PDQ-39, PDQSI

\section{Introduction}

The nonmotor symptoms (NMS) of Parkinson's disease (PD) are recognized as important disability-causing factors. NMS include autonomic dysfunction, ${ }^{1}$ neuropsychological problems, ${ }^{2}$ sleep disturbance, ${ }^{3,4}$ and sensory symptoms. ${ }^{5}$ These symptoms constitute a burden on the caregiver and the public health system. In the PRIAMO study, ${ }^{6}$ up to $98.6 \%$ of PD patients had NMS. Recently, the correlation between NMS and PD patients' health-related quality of life (HRQoL) has been emphasized. Several studies indicate that NMS, rather than motor symptoms, are a major cause of poor HRQoL. ${ }^{7-9}$ The NMS screening questionnaire (NMSQuest), a self-completed questionnaire comprising 30 items, is a rapid screening tool for the early detection of patients' NMS. ${ }^{10,11}$ Previous studies have compared NMS in different countries and showed more prevalent gastrointestinal symptoms in Asian countries, probably due to ethnic and economic differences. ${ }^{12,13}$ However, the NMSQuest is still not routinely used for Taiwanese PD patients. Demographic data regarding NMS in Taiwanese PD patients remain unknown. 
The pathophysiology of NMS is suspected to involve dopamine, noradrenaline, and serotonin. A previous review indicated that current dopaminergic anti-Parkinson medication has a limited effect on NMS. ${ }^{14}$ Although dopamine agonists reportedly have some antidepression effects, ${ }^{15,16}$ they also precipitate other NMS, such as orthostatic hypotension, hallucination, and impulse control diorder ${ }^{17-19}$ Thus, whether dopamine agonists improve patients' NMS and HRQoL remains a point of controversy.

The purpose of our study is to investigate the prevalence of NMS in PD patients in Taiwan and the impact of NMS on HRQoL since few studies on NMS have been conducted in Asian PD patients and the effects of anti-PD drugs, especially dopamine agonists, on risk of NMS are still controversial. We therefore conducted this hospital-based cross-sectional study to examine the clinical factors, including concomitant anti-PD medication use, on the occurrence of NMS and HRQoL in Taiwanese PD patients. We used the NMSQuest and 39-item Parkinson's Disease Questionnaire (PDQ-39) to explore the correlation among NMS, clinical factors, pharmacological therapy, and HRQoL.

\section{Materials and methods}

\section{Patients}

This cohort study was conducted in the neurology department of National Taiwan University Hospital (NTUH), a tertiary referred medical center in Taipei, Taiwan. From February 2014 to December 2014, PD patients who fulfilled the United Kingdom Parkinson's Disease Brain Bank Criteria ${ }^{20}$ and received long-term follow-up in NTUH movement disorder clinics were recruited. Patients who were diagnosed with atypical parkinsonism or secondary parkinsonism were excluded. Since the National health insurance of Taiwan pays the cost of the anti-cholinesterase inhibitor, rivastigmine, for subjects with PD with dementia, we therefore excluded subjects with concomitant use of rivastigmine to exclude participants with PD with dementia. ${ }^{21}$ All patients in this study provided written informed consent. The study was approved by the Ethical Research Committee of NTUH.

\section{Measures}

Patients who fulfilled the diagnostic criteria were asked to complete the Chinese version of the NMSQuest ${ }^{22}$ and PDQ-3923 while they were in the waiting room of the clinic. Previous studies have validated the Chinese versions of these two tests and the reliability of each domain of these two tests in the Chinese version are between $71 \%$ and $95 \%$, which represents an acceptable psychometric property.
If necessary, aid from patients' caregivers or a nurse was acceptable. Demographic data, including patients' age, sex, age at onset, duration, Hoehn and $\mathrm{Yahr}(\mathrm{H} \& \mathrm{Y})$ stage, disease type, and current medication, were collected from medical records. Patients' disease type was classified as tremor-atonset type or bradykinesia/rigidity-at-onset type by review of their medical record, depending on their initial presentation at their first visit to our clinics. ${ }^{24,25}$ Individuals with resting tremor predominant as initial presentation were classified as tremor-at-onset type; others were classified as bradykinesia/ rigidity-at-onset type.

The NMSQuest is a validated self-completed yes-no-type questionnaire to assess patients' NMS. This 30 -items questionnaire measure nine domains of NMS: digestive, urinary, sexual, cardiovascular, memory/apathy, hallucination/ delusion, depression/anxiety, sleep, and miscellany. ${ }^{10}$ Positive responses are summed up to yield a total score (NMSQT) that ranges from 0 to 30 . Higher scores indicate worse NMS condition. ${ }^{11}$ The prevalence of each item was calculated on the total 210 samples by computing the number of positive responses and transforming them into a percentage. Positive answers in each domain were summed to obtain the score for the domain. The standardized prevalence of each domain was calculated by the number of positive responses divided by the total number of responses in the domain and transforming this values into a percentage.

Patients' HRQoL was assessed by the PDQ- $39,{ }^{7}$ which contains 39 items. Each item was rated by the patients using one of five categories, from 0 (never) to 4 (very frequent). PDQ-39 summary index (PDQSI) was calculated by dividing the sum of the total raw score by the maximum possible score (156 or 152 points, depending on the patient's marriage status) and multiplying by 100. In this study, we used PDQSI as a standardized index for representing PD patients' life quality.

\section{Statistical analysis}

Spearman's rank correlation coefficient was calculated to check the correlation between clinical factors, pharmacological therapy, NMSQT, and PDQSI. $P$-values of less than 0.05 were accepted as significant. The strength of the association for correlation coefficients was interpreted as follows: $\leq 0.19$, negligible correlation; $0.20-0.39$, weak correlation; $0.40-0.59$, moderate correlation; $0.60-0.79$, strong correlation; and $\geq 0.80$, very strong correlation. ${ }^{26}$ A stepwise multiple linear regression analysis was calculated to demonstrate which clinical factors contributed significantly to NMSQT. Age, sex, age at PD onset, duration of PD symptoms, H\&Y stage, levodopa dosage, and dopamine agonist 
dosage (transformed into levodopa-equivalent dosage $)^{27}$ were involved as independent variables. Owing to collinearity between patients' current age and their age at disease onset $(r=0.92)$, age at PD onset was transformed into dummy variables $(<50$ years $=0 ; \geq 50$ years $=1)$. Stepwise multiple linear regression analysis was also applied to assess the contribution of clinical factors to the PDQSI. For the regression model of PDQSI, we involved the aforementioned factors and NMSQT as independent variables.

To compare our prevalence of each symptom with others', we chose two international studies (one included only Europe and USA, the other included Europe, USA, Israel, and Japan) and one study from People's Republic of China. $\chi^{2}$ test was used for comparison (Table S1). ${ }^{10,28,29}$ SPSS version 22.0 was used for the statistical analyses.

\section{Results}

We collected data from 210 patients ( 110 males, 100 females; mean age: $66.1 \pm 9.86$ years; median: 67 years; mode: 63 years; age range: $33-86$ years; mean age at onset: $60 \pm 10.53$ years; median: 61 years; mode: 61 years; onset age range: 26-83; disease duration 6.11 \pm 4.13 years; and H\&Y stage $2.2 \pm 0.9)$. Demographic data are shown in Table 1. Half of

Table I Demographic, clinical, and medical characteristics for our subjects

\begin{tabular}{|c|c|c|}
\hline & & Range \\
\hline Patients, $n$ & 210 & \\
\hline Male/female & $110 / 100$ & \\
\hline Mean age $\pm S D$, years & $66.1 \pm 9.86$ & $33-86$ \\
\hline Mean age at onset $\pm S D$, years & $60 \pm 10.53$ & $26-83$ \\
\hline Age $\geq 50 /$ age $<50, n$ & $173 / 37$ & \\
\hline Mean disease duration \pm SD, years & $6.11 \pm 4.13$ & $0-23$ \\
\hline \multicolumn{3}{|l|}{ H\&Y stage, n (\%) } \\
\hline Stage I & $47(22.4)$ & \\
\hline Stage 2 & $98(46.7)$ & \\
\hline Stage 3 & $44(21.0)$ & \\
\hline Stage 4 & $20(9.5)$ & \\
\hline Stage 5 & I (0.5) & \\
\hline \multicolumn{3}{|l|}{ Disease type at onset, n (\%) } \\
\hline Tremor & 102 (48.6) & \\
\hline Bradykinesia/rigidity & $108(5 \mid .4)$ & \\
\hline \multicolumn{3}{|l|}{ Medication, n (\%) } \\
\hline Levodopa & 205 (97.6) & \\
\hline Dopamine agonist & $170(8 \mid)$ & \\
\hline BZD & $75(35.7)$ & \\
\hline $\mathrm{MAOBI}$ & $36(17.1)$ & \\
\hline Antidepressant & $7(3.3)$ & \\
\hline Antipsychotics & $10(4.8)$ & \\
\hline Anticholinergics & $59(28.1)$ & \\
\hline Amantadine & $97(46.2)$ & \\
\hline
\end{tabular}

Abbreviations: BZD, benzodiazepines; $\mathrm{H} \& \mathrm{Y}$, Hoehn and Yahr; $\mathrm{MAOBI}$, monoamine oxidase $B$ inhibitor; $S D$, standard deviation. our subjects were in H\&Y stage 2. Most of our patients were using levodopa (97.6\%) and dopamine agonists (81\%).

The result of NMSQuest and PDQ-39 are shown in Table 2. The mean NMSQT was $7.77 \pm 4.74$, which was considered as moderate in severity according to a previous study. ${ }^{11}$ The prevalence of NMS was $98.57 \%$. Only three patients had no NMS. Among $30 \mathrm{NMS}$, nocturia was the most frequently reported NMS (prevalence $=62.86 \%$ ). Constipation was the second most prevalent problem among patients (prevalence $=50.95 \%$ ). The least frequent complaint was bowel incontinence, which happened in $2.86 \%$ of patients (Table S1). Of the nine NMS subdomains, the urinary domain had the highest prevalence $(56.19 \%)$, followed by memory/ apathy $(30.48 \%)$ and depression/anxiety $(27.86 \%)$, while hallucination/delusion had the lowest prevalence $(9.76 \%)$. The mean PDQSI was 16.13 \pm 15.61 .

Spearman's rank correlation coefficients indicated that the NMSQT and all subdomains correlated with the PDQSI (Table 3). NMSQT had stronger correlation with PDQSI than H\&Y stage $\left(r_{\mathrm{s}}\right.$ of NMSQT $=0.667 ; r_{\mathrm{s}}$ of H\&Y stage $\left.=0.503\right)$. Among nine NMS subdomains, depression/anxiety correlated most strongly with PDQSI $\left(r_{\mathrm{s}}=0.607\right)$, while the urinary domain exhibited the weakest correlation $\left(r_{\mathrm{s}}=0.172\right)$. Age and disease types at onset did not significantly correlate with NMSQT and PDQSI, but there was significant difference between sexes in some NMS subdomains (Table S2). Females had higher scores in memory/apathy and depression/ anxiety (prevalence of memory/apathy, female vs male: $57 \%$

Table 2 Descriptive statistics of the NMSQT and PDQ-39 rating scales in 210 Taiwanese patients with Parkinson's disease

\begin{tabular}{|c|c|c|c|}
\hline & Prevalence, \% & $\begin{array}{l}\text { Mean } \\
\text { score } \pm \text { SD }\end{array}$ & Range \\
\hline \multicolumn{4}{|c|}{ NMSQuest (number of items) } \\
\hline NMSQuest total score (30) & 98.57 & $7.77 \pm 4.74$ & $0-24$ \\
\hline \multicolumn{4}{|l|}{ NMSQT domains } \\
\hline Digestive (7) & 24.97 & $\mathrm{I} .75 \pm \mathrm{I} .38$ & $0-6$ \\
\hline Urinary (2) & 56.19 & $1.12 \pm 0.74$ & $0-2$ \\
\hline Sexual dysfunction (2) & 23.81 & $0.48 \pm 0.73$ & $0-2$ \\
\hline Cardiovascular (2) & 24.29 & $0.49 \pm 0.62$ & $0-2$ \\
\hline Memory/apathy (3) & 30.48 & $0.91 \pm 1.06$ & $0-3$ \\
\hline Hallucination/delusion (2) & 9.76 & $0.20 \pm 0.48$ & $0-2$ \\
\hline Depression/anxiety (2) & 27.86 & $0.56 \pm 0.8 \mathrm{I}$ & $0-2$ \\
\hline Sleep disorders (5) & 30.00 & $1.50 \pm 1.34$ & $0-5$ \\
\hline Miscellany (5) & 15.43 & $0.77 \pm 0.97$ & $0-5$ \\
\hline \multicolumn{4}{|l|}{ PDQ-39 } \\
\hline PDQ-39 total scores & & $25.11 \pm 24.30$ & $0-125$ \\
\hline PDQ-39 summary index & & $|6.13 \pm| 5.6 \mid$ & $0-119$ \\
\hline
\end{tabular}

Abbreviations: NMSQT, nonmotor symptoms questionnaire total score; PDQ39, 39-item Parkinson's Disease Questionnaire; SD, standard deviation; NMSQuest, nonmotor symptoms questionnaire. 
Table 3 Correlations of scores of NMSQuest, Hoehn and Yahr stage, and PDQSI

\begin{tabular}{lll}
\hline & $\boldsymbol{r}_{\mathrm{s}}$ & $\boldsymbol{P}$-value \\
\hline Hoehn and Yahr stage & 0.503 & $<0.00 \mathrm{I}$ \\
NMSQT & 0.667 & $<0.00 \mathrm{I}$ \\
Digestive & 0.336 & $<0.00 \mathrm{I}$ \\
Urinary & 0.172 & 0.013 \\
Sexual dysfunction & 0.253 & 0.006 \\
Cardiovascular & 0.403 & $<0.001$ \\
Memory/apathy & $0.4 \mathrm{II}$ & $<0.001$ \\
Hallucination/delusion & $0.37 \mathrm{I}$ & $<0.001$ \\
Depression/anxiety & 0.607 & $<0.001$ \\
Sleep disorders & $0.46 \mathrm{I}$ & $<0.00 \mathrm{I}$ \\
Miscellany & 0.376 & $<0.00 \mathrm{I}$ \\
\hline
\end{tabular}

Abbreviations: NMSQT, nonmotor symptoms questionnaire total score; NMSQuest, nonmotor symptoms questionnaire; $r_{s}$, Spearman's rank correlation coefficient; PDQSI, 39-item Parkinson's Disease Questionnaire summary index.

vs $47 \%$, average score: 1.1 vs 0.75 ; prevalence of depression/ anxiety, female vs male: $42 \%$ vs $29 \%$, average score: 0.69 vs 0.44$)$. Males had higher a score in sexual symptoms (prevalence of sexual dysfunction, female vs male: $26 \%$ vs $41 \%$, average score: 0.34 vs 0.6 ). The PDQSI, NMSQT, and almost all NMS subdomains were correlated positively with disease duration, H\&Y stage, and levodopa dosage. However, dopamine agonist dosage did not correlate significantly with the PDQSI, NMSQT, or almost all subdomains.

The regression model for the NMSQT indicated that duration of disease and $\mathrm{H} \& \mathrm{Y}$ stage were independent variables (Table 4). The regression model for the PDQSI revealed that independent variables included NMSQT, H\&Y stage, age at onset, and sex (Table 4).

\section{Discussion}

This was the first study, to our knowledge, to use NMSQuest to evaluate NMS in Taiwanese PD patients. In our study of 210 PD patients, we observed a high prevalence rate of NMS (98.57\%). Among nine subdomains, the most prevalent domains were urinary complaints, followed by memory/ apathy and depression/anxiety. NMSQT and all subdomains were correlated with the PDQSI. Among those subdomains, depression/anxiety had the strongest correlation coefficient with the HRQoL of PD patients. The regression model indicated that disease duration and severity were major predictors of NMS. Concomitant use of anti-PD medication, including dopamine agonist, was not correlated with the occurrence of NMS or HRQoL of patients with PD.

The general prevalence of NMS in our study was close to that of previous studies in other countries (Table S3). ${ }^{10,13,28-38}$ This indicates that NMS are very frequent and universal concerns in PD patients. ${ }^{6}$ For each item in NMSQuest, we compared our study with the studies of Chaudhuri et al, ${ }^{10}$ Martinez-Martin et al, ${ }^{28}$ and Gan et al. ${ }^{29}$ The results showed that there were no significant differences in most NMS rates between studies (Table S1). The three most common symptoms in our study were nocturia $(62.85 \%)$, constipation (50.95\%), and urgency (49.52\%), and the least common symptom was bowel incontinence $(2.86 \%)$. This result was the same as Chaudhuri ${ }^{10}$ and Martinez-Martin's studies ${ }^{28}$ in Europe and USA. In contrast, studies in the People's Republic of China ${ }^{29-32}$ revealed that the most common symptom was easily forgetting (prevalence: $56.1 \%-68.56 \%$ ) (Table S3). This suggests that factors other than race, such as age, disease duration, treatment strategy, education, and economical status, may be more influential on NMS. Further study for comparison among groups is needed. Previous studies have suggested that Asian PD patients may have higher rates of constipation or gastrointestinal problems. ${ }^{12,13}$ However, our study and one recent large-scale study from the People's Republic of China $^{30}$ showed that constipation rates were not higher than Western groups (Table S3). Ethnic effect on NMS is still controversial.

Although urinary symptoms were the most common in patients, the correlation between urinary symptoms and

Table 4 Multiple linear regression analysis for NMSQT and PDQSI

\begin{tabular}{|c|c|c|c|c|}
\hline & Standardized beta & Standard error & $95 \% \mathrm{Cl}$ & $P$-value \\
\hline \multicolumn{5}{|c|}{ Regression model of the NMSQT } \\
\hline \multicolumn{5}{|l|}{ (Adjusted $R^{2}=0.574$ ) } \\
\hline $\mathrm{H} \& \mathrm{Y}$ & 0.241 & 0.390 & $0.49-2.03$ & 0.001 \\
\hline Duration (years) & 0.208 & 0.086 & $0.07-0.4 I$ & 0.006 \\
\hline \multirow{2}{*}{\multicolumn{5}{|c|}{$\begin{array}{l}\text { Regression model of the PDQSI } \\
\text { (Adjusted } R^{2}=0.613 \text { ) }\end{array}$}} \\
\hline & & & & \\
\hline $\mathrm{H} \& \mathrm{Y}$ & 0.402 & 0.793 & $5.35-8.48$ & $<0.001$ \\
\hline NMSQT & 0.509 & 0.153 & $1.38-1.98$ & $<0.001$ \\
\hline Age at onset & -0.113 & 1.776 & -8.13 to -1.126 & 0.01 \\
\hline Sex & -0.175 & 1.349 & -8.11 to -2.78 & $<0.001$ \\
\hline
\end{tabular}

Abbreviations: $\mathrm{Cl}$, confidence interval; H\&Y, Hoehn and Yahr stage; NMSQT, nonmotor symptoms questionnaire total score; PDQSI, 39-item Parkinson's Disease Questionnaire summary index. 
HRQoL was lowest $\left(r_{\mathrm{s}}=0.176\right)$. This may be due to the fact that urinary symptoms rarely induce motor disturbance and psychosocial problems, which are mainly evaluated in PDQ-39. Measurement bias should be carefully considered when evaluating the impact of urinary symptoms on patients' life quality. Neuropsychological symptoms exerted the greatest influence over our patients' quality of life; among those, depression/apathy correlated most strongly with PDQSI ( $r=0.607)$. This finding is consistent with previous studies indicating that depression has the greatest impact on PD patients. ${ }^{8,12,26,28,39}$ In our study, $30 \%$ of patients selfreported having depressed mood, which was compatible with the newest meta-analysis on the prevalence of depression among individuals with a PD diagnosis (36.6\%). ${ }^{40}$ Depression is two- to threefold more prevalent among PD patients compared to healthy people, and can precede the diagnosis of PD by 4-6 years. ${ }^{41}$ This evidence suggests an underlying neurodegenerative process for depression in PD patients. Braak et al's pathology study demonstrated that the degeneration of PD is not limited to the substantia nigra; it also affects the locus coeruleus and raphe nucleus before the beginning of PD motor symptoms. ${ }^{42}$ This finding indicates that noradrenaline and serotonin were also involved in the pathology of depression in PD. Positron emission tomography has provided evidence of decreasing dopamine and noradrenaline transporter levels in the locus coeruleus and several regions of limbic system. ${ }^{43}{ }^{18} \mathrm{~F}$-fluorodeoxyglucose positron emission tomography has shown decreasing availability of the serotonergic $1 \mathrm{~A}$ receptor in the limbic and orbitofrontal regions. ${ }^{44}$ Several studies that employed resting-state functional magnetic resonance imaging have revealed reduced functional connectivity in the prefrontallimbic network in PD patients with depression. ${ }^{45-47}$

Pramipexole was found to improve depression in 12 weeks in 323 depressive PD patients. ${ }^{15}$ In that study, the Beck Depression Inventory score decreased by 5.9 points in the pramipexole group, compared with 4.0 points in the placebo group. In another study that involved only 44 patients, the Hamilton Anxiety Scale and the Montgomery-Asberg Depression Rating Scale also dropped in PD patients using ropinirole. ${ }^{48}$ However, in the present study, we did not find a significant correlation between calculated dopamine agonist dosage and NMSQT (including all subdomains) (Table S2). In addition, we compared NMSQT, score of depression/ anxiety subdomain, and PDQSI between the patients with and without using dopamine agonists. None of those showed significant difference (Mann-Whitney test; NMSQT: $P=0.766$; depression/anxiety: $P=0.111$; PDQSI: $P=0.406$ ). The negative results indicate that dopamine agonists did not eliminate depression and might not improve patients' life quality. However, only a yes/no question can be answered for each symptom in NMSQuest. Dopamine agonists cannot completely eliminate depressive symptoms but they may partially relieve the depression symptoms. The NonMotor Symptoms Scale, ${ }^{49}$ another assessment tool which is able to evaluate the severity of each symptom, should be applied for further evaluation of dopamine agonists' antidepression effects.

Our regression model demonstrates that only disease severity and duration are independent variables for NMSQT. In contrast to Martinez-Martin et al's study, ${ }^{28}$ our regression model does not reveal age of onset as an independent predictor. In our correlation study, patients with young-onset PD (YOPD) surprisingly had higher NMSQT and PDQSI (ie, worse HRQoL), possibly because our YOPD group featured longer disease duration (YOPD vs late-onset PD [LOPD]: 7.9 years vs 5.8 years). The other regression model for PDQSI indicates that NMSQT, H\&Y stage, age at onset, and sex are independent values, in which NMSQ plays the most important role. This result is quite similar to previous studies' findings that NMS are the major predictor for patients' quality of life, suggesting that NMS cause more disability than motor symptoms. ${ }^{7-9}$ In our regression model for PDQSI, sex and age at onset were also independent values, although they have minor roles. Looking at our data (Figure 1), YOPD and female patients had similar NMSQT (YOPD vs LOPD: 9.41 vs 7.48, $P=0.238$; female vs male: 7.95 vs $7.61, P=0.784$ ). However, they had slightly higher PDQSI (YOPD vs LOPD: 22.3 vs $15.02, P=0.008$; female vs male: 18.77 vs 13.74 , $P=0.202)$. This may indicate that, although they had similar number of NMS, they still subjectively felt that they had a poor life quality. In Dubayova et al's study, ${ }^{50}$ females also had slightly higher PDQ-39 scores although there was no significant difference. In female patients, age and neuroticism were more significantly correlated with PDQ-39 score than they were in males. In Nutt et al's study, ${ }^{51}$ multiple linear regression showed age and sex were independent variables contributing to PDQSI.

There are several limitations in the current study. Although our sample number is relatively small, it is comparable to other studies (Table S3). In addition, another limitation of our study is that few YOPD patients were involved $(n=32)$, which may partly explain why age at onset did not play an important role in our study. Although YOPD predicts higher NMSQT in Martinez-Martin et al's study, ${ }^{28}$ another study indicated that patients with LOPD have more gastrointestinal and urinary symptoms, dementia, and psychosis, which influence patients' 


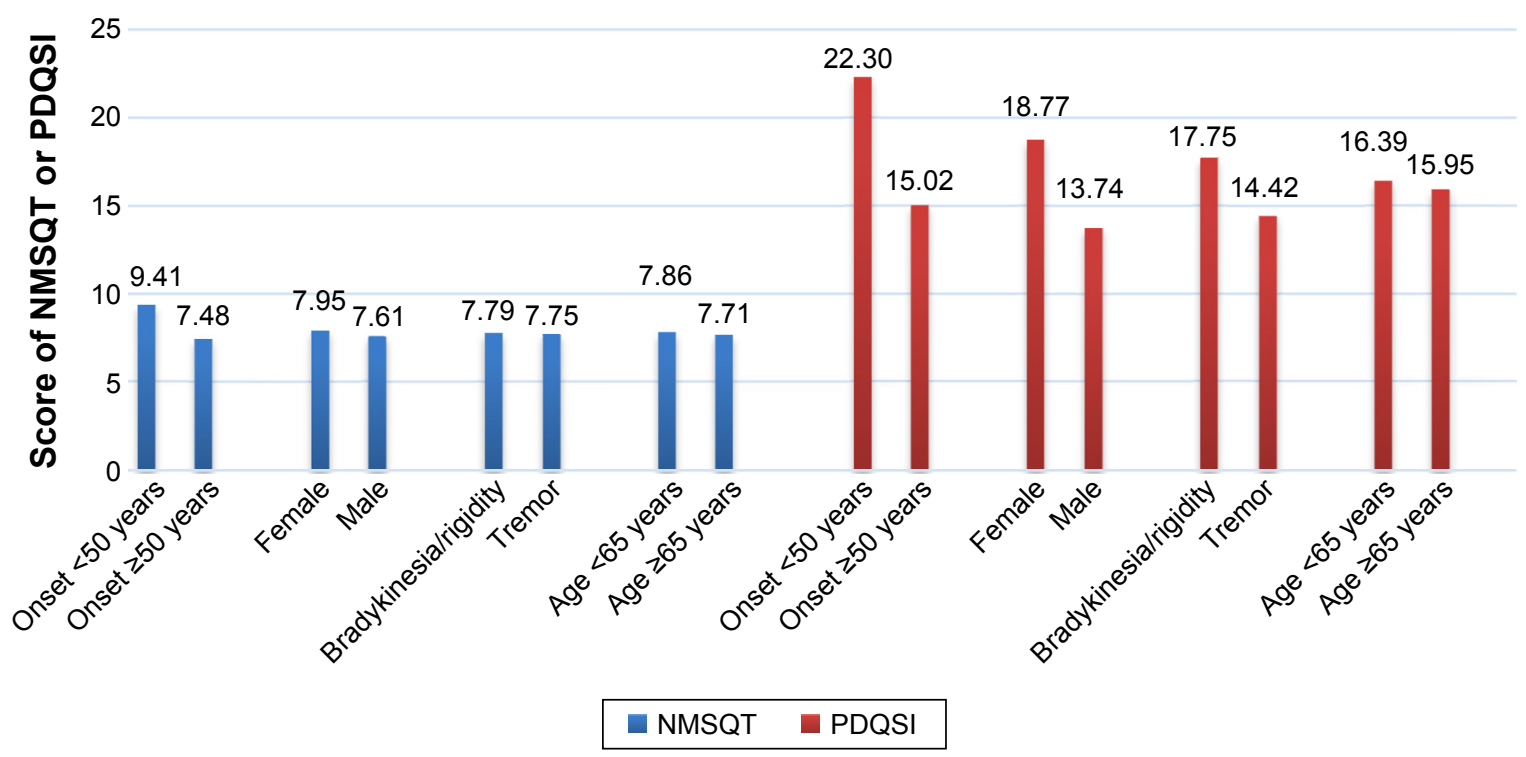

Figure I Comparison of NMSQT and PDQSI between different groups of onset age, sex, disease at onset, and current age.

Abbreviations: NMSQT, nonmotor symptoms questionnaire total score; PDQSI, 39-item Parkinson's Disease Questionnaire summary index.

quality of life more. ${ }^{52}$ To better understand the differences in NMS between YOPD and LOPD patients, more YOPD patients should be included in future studies.

\section{Conclusion}

Our findings indicate that NMS are common in PD patients and determine the life quality of PD patients. NMS severity is positively correlated with disease severity and duration. Among NMS subdomains, depression and other neuropsychological symptoms most influence patients' quality of life. However, concomitant anti-PD medication use did not affect the occurrence of NMS and quality of life. Further study for treatment of NMS is mandatory to improve the life quality of patients.

\section{Acknowledgment}

The authors thank all of those who participated in this study. This study was supported by Grant NTUH 101-S1889 and 103S2485 from National Taiwan University Hospital, Taiwan.

\section{Disclosure}

The authors report no financial disclosures or any conflicts of interest in this work.

\section{References}

1. Goldstein DS. Dysautonomia in Parkinson disease. Compr Physiol. 2014; $4(2): 805-826$.

2. de la Riva P, Smith K, Xie SX, Weintraub D. Course of psychiatric symptoms and global cognition in early Parkinson disease. Neurology. 2014; 83(12):1096-1103.

3. Jahan I, Hauser RA, Sullivan KL, Miller A, Zesiewicz TA. Sleep disorders in Parkinson's disease. Neuropsychiatr Dis Treat. 2009;5:535-540.
4. Yu RL, Tan $\mathrm{CH}, \mathrm{Wu} \mathrm{RM}$. The impact of nocturnal disturbances on daily quality of life in patients with Parkinson's disease. Neuropsychiatr Dis Treat. 2015;11:2005-2012.

5. Skogar O, Fall PA, Hallgren G, et al. Parkinson's disease patients' subjective descriptions of characteristics of chronic pain, sleeping patterns and health-related quality of life. Neuropsychiatr Dis Treat. 2012;8: 435-442.

6. Barone P, Antonini A, Colosimo C, et al. The PRIAMO study: A multicenter assessment of nonmotor symptoms and their impact on quality of life in Parkinson's disease. Mov Disord. 2009;24(11):1641-1649.

7. Martinez-Martin P, Rodriguez-Blazquez C, Kurtis MM, Chaudhuri KR; NMSS Validation Group. The impact of non-motor symptoms on health-related quality of life of patients with Parkinson's disease. Mov Disord. 2011;26(3):399-406.

8. Valkovic P, Harsany J, Hanakova M, Martinkova J, Benetin J. Nonmotor symptoms in early- and advanced-stage Parkinson's disease patients on dopaminergic therapy: how do they correlate with quality of life? ISRN Neurol. 2014;2014:587302.

9. Rodríguez-Violante M, Cervantes-Arriaga A, Corona T, MartínezRamírez D, Morales-Briceño H, Martínez-Martín P. Clinical determinants of health-related quality of life in Mexican patients with Parkinson's disease. Arch Med Res. 2013;44(2):110-114.

10. Chaudhuri KR, Martinez-Martin P, Schapira AH, et al. International multicenter pilot study of the first comprehensive self-completed nonmotor symptoms questionnaire for Parkinson's disease: the NMSQuest study. Mov Disord. 2006;21(7):916-923.

11. Chaudhuri KR, Sauerbier A, Rojo JM, et al. The burden of non-motor symptoms in Parkinson's disease using a self-completed non-motor questionnaire: a simple grading system. Parkinsonism Relat Disord. 2015; 21(3):287-291.

12. Azmin S, Khairul Anuar AM, Tan HJ, et al. Nonmotor symptoms in a Malaysian Parkinson's disease population. Parkinsons Dis. 2014;2014: 472157.

13. Tsuboi Y, Yamada T, Chaudhuri RK, et al. Comparison profile of non motor symptoms in Japanese patients with PD with European patients and healthy controls. Extension of the NMSQuest study. Mov Disord. 2006;21(supp115):S648.

14. Chaudhuri KR, Healy DG, Schapira AH, National Institute for Clinical Excellence. Non-motor symptoms of Parkinson's disease: diagnosis and management. Lancet Neurol. 2006;5(3):235-245. 
15. Barone P, Poewe W, Albrecht S, et al. Pramipexole for the treatment of depressive symptoms in patients with Parkinson's disease: a randomised, double-blind, placebo-controlled trial. Lancet Neurol. 2010; 9(6):573-580.

16. Ray Chaudhuri K, Martinez-Martin P, Antonini A, et al. Rotigotine and specific non-motor symptoms of Parkinson's disease: post hoc analysis of RECOVER. Parkinsonism Relat Disord. 2013;19(7):660-665.

17. Chaudhuri KR. Autonomic dysfunction in movement disorders. Curr Opin Neurol. 2001;14(4):505-511.

18. Poletti M, Perugi G, Logi C, et al. Dopamine agonists and delusional jealousy in Parkinson's disease: a cross-sectional prevalence study. Mov Disord. 2012;27(13):1679-1682.

19. Shapiro MA, Chang YL, Munson SK, et al. The four As associated with pathological Parkinson disease gamblers: anxiety, anger, age, and agonists. Neuropsychiatr Dis Treat. 2007;3(1):161-167.

20. Hughes AJ, Daniel SE, Kilford L, Lees AJ. Accuracy of clinical diagnosis of idiopathic Parkinson's disease: a clinico-pathological study of 100 cases. J Neurol Neurosurg Psychiatry. 1992;55(3):181-184.

21. Ku LJ, Pai MC. Use of cognitive enhancers and associated medical care costs among patients with dementia: a nationwide study in Taiwan. Int Psychogeriatr. 2014;26(5):795-804.

22. Li HJ, Zhang MF, Chen MX, et al. Validation of the nonmotor symptoms questionnaire for Parkinson's disease: results from a Chinese pilot study. Int J Neurosci. Epub 2014 Dec 18.

23. Ma HI, Hwang WJ, Chen-Sea MJ. Reliability and validity testing of a Chinese-translated version of the 39-item Parkinson's Disease Questionnaire (PDQ-39). Qual Life Res. 2005;14(2):565-569.

24. Hershey LA, Feldman BJ, Kim KY, Commichau C, Lichter DG. Tremor at onset. Predictor of cognitive and motor outcome in Parkinson's disease? Arch Neurol. 1991;48(10):1049-1051.

25. Dewey RB Jr, Taneja A, McClintock SM, et al. Motor symptoms at onset of Parkinson disease and risk for cognitive impairment and depression. Cogn Behav Neurol. 2012;25(3):115-120.

26. Li H, Zhang M, Chen L, et al. Nonmotor symptoms are independently associated with impaired health-related quality of life in Chinese patients with Parkinson's disease. Mov Disord. 2010;25(16):2740-2746.

27. Tomlinson CL, Stowe R, Patel S, Rick C, Gray R, Clarke CE. Systematic review of levodopa dose equivalency reporting in Parkinson's disease. Mov Disord. 2010;25(15):2649-2653.

28. Martinez-Martin P, Schapira AH, Stocchi F, et al. Prevalence of nonmotor symptoms in Parkinson's disease in an international setting; study using nonmotor symptoms questionnaire in 545 patients. Mov Disord. 2007;22(11):1623-1629.

29. Gan J, Zhou M, Chen W, Liu Z. Non-motor symptoms in Chinese Parkinson's disease patients. J Clin Neurosci. 2014;21(5):751-754.

30. Wu Y, Guo XY, Wei QQ, et al. Non-motor symptoms and quality of life in tremor dominant vs postural instability gait disorder Parkinson's disease patients. Acta Neurol Scand. Epub 2015 Jul 20.

31. Zhang N, Liu W, Ye M, Cohen AD, Zhang Y. The heterogeneity of non-motor symptoms of Parkinson's disease. Neurol Sci. 2015;36(4): 577-584.

32. Li DW, Gu Z, Wang C, et al. Non-motor symptoms in Chinese Parkinson's disease patients with and without LRRK2 G2385R and R1628P variants. J Neural Transm. 2015;122(5):661-667.

33. Cheon SM, Ha MS, Park MJ, Kim JW. Nonmotor symptoms of Parkinson's disease: prevalence and awareness of patients and families. Parkinsonism Relat Disord. 2008;14(4):286-290.

34. Rukmini Mridula K, Borgohain R, Jabeen SA, et al. Comparison of frequencies of non motor symptoms in Indian Parkinson's disease patients on medical management versus deep brain stimulation: A case-control study. Iran J Neurol. 2015;14(2):86-93
35. Cosentino C, Nuñez Y, Torres L. Frequency of non-motor symptoms in Peruvian patients with Parkinson's disease. Arq Neuropsiquiatr. 2013;71(4):216-219.

36. Khedr EM, El Fetoh NA, Khalifa H, Ahmed MA, El Beh KM. Prevalence of non motor features in a cohort of Parkinson's disease patients. Clin Neurol Neurosurg. 2013;115(6):673-677.

37. Bostantjopoulou S, Katsarou Z, Karakasis C, Peitsidou E, Milioni D, Rossopoulos N. Evaluation of non-motor symptoms in Parkinson's Disease: An underestimated necessity. Hippokratia. 2013;17(3):214-219.

38. Crosiers D, Pickut B, Theuns J, et al. Non-motor symptoms in a Flanders-Belgian population of 215 Parkinson's disease patients as assessed by the Non-Motor Symptoms Questionnaire. Am J Neurodegener Dis. 2012;1(2):160-167.

39. Slawek J, Derejko M, Lass P. Factors affecting the quality of life of patients with idiopathic Parkinson's disease - a cross-sectional study in an outpatient clinic attendees. Parkinsonism Relat Disord. 2005;11(7):465-468.

40. Chen H, Zhao EJ, Zhang W, et al. Meta-analyses on prevalence of selected Parkinson's nonmotor symptoms before and after diagnosis. Transl Neurodegener. 2015;4(1):1.

41. Ishihara L, Brayne C. A systematic review of depression and mental illness preceding Parkinson's disease. Acta Neurol Scand. 2006;113(4): 211-220.

42. Braak H, Del Tredici K, Rüb U, de Vos RA, Jansen Steur EN, Braak E. Staging of brain pathology related to sporadic Parkinson's disease. Neurobiol Aging. 2003;24(2):197-211.

43. Remy P, Doder M, Lees A, Turjanski N, Brooks D. Depression in Parkinson's disease: loss of dopamine and noradrenaline innervation in the limbic system. Brain. 2005;128(Pt 6):1314-1322.

44. Ballanger B, Klinger $\mathrm{H}$, Eche J, et al. Role of serotonergic $1 \mathrm{~A}$ receptor dysfunction in depression associated with Parkinson's disease. Mov Disord. 2012;27(1):84-89.

45. Iwabuchi SJ, Krishnadas R, Li C, Auer DP, Radua J, Palaniyappan L. Localized connectivity in depression: a meta-analysis of resting state functional imaging studies. Neurosci Biobehav Rev. 2015;51:77-86.

46. Luo C, Chen Q, Song W, et al. Resting-state fMRI study on drug-naive patients with Parkinson's disease and with depression. J Neurol Neurosurg Psychiatry. 2014;85(6):675-683.

47. Sheng K, Fang W, Su M, et al. Altered spontaneous brain activity in patients with Parkinson's disease accompanied by depressive symptoms, as revealed by regional homogeneity and functional connectivity in the prefrontal-limbic system. PLoS One. 2014;9(1):e84705.

48. Rektorova I, Balaz M, Svatova J, et al. Effects of ropinirole on nonmotor symptoms of Parkinson disease: a prospective multicenter study. Clin Neuropharmacol. 2008;31(5):261-266.

49. Chaudhuri KR, Martinez-Martin P, Brown RG, et al. The metric properties of a novel non-motor symptoms scale for Parkinson's disease: Results from an international pilot study. Mov Disord. 2007;22(13): 1901-1911.

50. Dubayova T, Nagyova I, Havlikova E, et al. Neuroticism and extraversion in association with quality of life in patients with Parkinson's disease. Qual Life Res. 2009;18(1):33-42.

51. Nutt JG, Siderowf AD, Guttman M, et al. Mobility, mood and site of care impact health related quality of life in Parkinson's disease. Parkinsonism Relat Disord. 2014;20(3):274-279.

52. Spica V, Pekmezović T, Svetel M, Kostić VS. Prevalence of nonmotor symptoms in young-onset versus late-onset Parkinson's disease. J Neurol. 2013;260(1):131-137. 


\section{Supplementary materials}

Table SI Comparison of the prevalence of each nonmotor symptom with other studies

\begin{tabular}{|c|c|c|c|c|c|c|c|}
\hline & $\begin{array}{l}\text { Current } \\
\text { study (\%) }\end{array}$ & $\begin{array}{l}\text { Martinez- } \\
\text { Martin et al' (\%) }\end{array}$ & $\begin{array}{l}P \text {-value } \\
\left(\chi^{2} \text { test }\right)\end{array}$ & $\begin{array}{l}\text { Chaudhuri } \\
\text { et } \mathrm{al}^{2}(\%)\end{array}$ & $\begin{array}{l}P \text {-value } \\
\left(\chi^{2} \text { test }\right)\end{array}$ & Gan et $\mathrm{al}^{3}(\%)$ & $\begin{array}{l}\text { P-value } \\
\left(\chi^{2} \text { test }\right)\end{array}$ \\
\hline Dribbling & 27.14 & 41.52 & $0.026^{*}$ & 35 & 0.14 & 17.70 & 0.128 \\
\hline Taste/smelling & 16.19 & 28.95 & $0.028 *$ & 26 & 0.054 & 22.20 & 0.279 \\
\hline Swallowing & 29.52 & 28.38 & 0.755 & 23.6 & 0.433 & 23.40 & 0.28 \\
\hline Vomiting & 12.38 & $|4.3|$ & 0.674 & 8.1 & 0.397 & 8.20 & 0.358 \\
\hline Constipation & 50.95 & 52.48 & 0.887 & 46.7 & 0.831 & 64.60 & $0.036 *$ \\
\hline Bowel incontinence & 2.86 & 8.21 & 0.121 & 4.9 & 0.435 & 0.60 & 0.312 \\
\hline Bowel emptying incomplete & 35.71 & 29.90 & 0.367 & 27.6 & 0.308 & 15.20 & $0.001 *$ \\
\hline Urgency & 49.52 & 55.81 & 0.395 & 61 & $0.022 *$ & 31.00 & $0.006 *$ \\
\hline Nocturia & 62.86 & 61.90 & 0.884 & 66.7 & 0.116 & 61.40 & 0.84 \\
\hline Pains & 22.86 & 28.76 & 0.333 & 27.6 & 0.225 & 27.20 & 0.487 \\
\hline Weight & 16.67 & 18.29 & 0.852 & 22 & 0.25 & 22.20 & 0.353 \\
\hline Memory & 38.10 & 44.85 & 0.315 & 43.9 & 0.169 & 65.80 & $<0.00 I^{*}$ \\
\hline Loss of interest & 26.19 & 34.67 & 0.167 & 29.3 & 0.425 & 48.70 & $<0.00 I^{*}$ \\
\hline Hallucinations & 13.33 & 22.52 & 0.066 & 19.5 & 0.143 & $\mathrm{II} .40$ & 0.663 \\
\hline Concentrating & 27.14 & 45.71 & $0.005^{*}$ & 37.4 & $0.03 *$ & 38.00 & 0.097 \\
\hline Sadness/blues & 30.00 & 50.10 & $0.004 *$ & 44.7 & $0.018^{*}$ & 36.70 & 0.228 \\
\hline Anxiety & 25.71 & 45.33 & $0.005 *$ & 39.9 & $0.011 *$ & 30.40 & $0.47 \mid$ \\
\hline Sex drive & 24.29 & 34.17 & 0.119 & 29.3 & 0.073 & 16.50 & 0.296 \\
\hline Sex difficulty & 23.33 & 32.43 & 0.154 & 24.4 & 0.166 & 12.00 & 0.064 \\
\hline Dizzy & 34.76 & 37.14 & 0.768 & 39.8 & 0.308 & 16.50 & $0.004 *$ \\
\hline Falling & $|3.8|$ & 28.00 & $0.015^{*}$ & 30.9 & $0.002^{*}$ & 25.90 & $0.031 *$ \\
\hline Daytime sleepiness & 12.86 & 31.11 & $0.002^{*}$ & 28.4 & $0.005^{*}$ & 38.60 & $<0.00 I^{*}$ \\
\hline Insomnia & 37.14 & 45.71 & 0.196 & 40.6 & 0.414 & 39.20 & 0.728 \\
\hline Vivid dreams & 39.52 & 33.90 & 0.38 & 30.9 & 0.31 & 43.70 & 0.486 \\
\hline RBD & 35.24 & 35.69 & 0.883 & 32.5 & 0.927 & 27.80 & 0.332 \\
\hline Restless legs & 25.24 & 41.71 & $0.011 *$ & 37.4 & $0.024^{*}$ & 20.30 & 0.419 \\
\hline Swelling & 14.29 & 31.30 & $0.004^{*}$ & 30.9 & $0.001 *$ & 8.20 & 0.183 \\
\hline Sweating & 10.48 & 29.90 & $<0.00 I^{*}$ & 25.2 & $0.002^{*}$ & 28.50 & $0.001 *$ \\
\hline Diplopia & 12.86 & 20.00 & 0.182 & 21.9 & 0.065 & 5.70 & 0.096 \\
\hline Delusions & 6.19 & 11.07 & 0.205 & 12.3 & 0.11 & 12.00 & 0.132 \\
\hline
\end{tabular}

Notes: *Indicates statistical significance. Adapted with permission from Martinez-Martin P, Schapira AH, Stocchi F, et al. Prevalence of nonmotor symptoms in Parkinson's disease in an international setting; study using nonmotor symptoms questionnaire in 545 patients. Movement Disorders. 2007;22(I I): I623-I629. Published by John Wiley and Sons. Copyright @ 2007 Movement Disorder Society.' And adapted with permission from Chaudhuri KR, Martinez-Martin P, Schapira AH, et al. International multicenter pilot study of the first comprehensive self-completed nonmotor symptoms questionnaire for Parkinson's disease: the NMSQuest study. Movement Disorders. 2006;2I (7):916-923. Published by John Wiley and Sons. Copyright (c) 2006 Movement Disorder Society. ${ }^{2}$ And adapted from Journal of Clinical Neuroscience. 20I 4;2I (5). Gan J, Zhou M, Chen W, Liu Z. Non-motor symptoms in Chinese Parkinson's disease patients. 75I-754. With permission from Elsevier. Copyright @) 2013 Elsevier Ltd. All rights reserved. ${ }^{3}$

Abbreviation: RBD, rapid eye movement sleep behavior disorder.

Table S2 Correlations of clinical factors with NMSQT, subdomains, and PDQSI

\begin{tabular}{|c|c|c|c|c|c|c|c|c|c|c|c|c|c|}
\hline & NMSQT & Digestive & $\mathbf{U}$ & M/A & H/D & Dep/An & Sexual ${ }^{\#}$ & $\mathrm{CV}$ & Sleep & Mis & Auto & NP & PDQSI \\
\hline $\operatorname{Sex}\left(r_{s}\right)$ & -0.019 & 0.054 & 0.072 & -0.144 & -0.033 & -0.15 & 0.172 & $-0.07 \mid$ & 0.057 & -0.106 & 0.078 & -0.155 & -0.088 \\
\hline (P-value) & 0.785 & 0.428 & 0.301 & $0.037 *$ & 0.633 & $0.03^{*}$ & $0.013^{*}$ & 0.303 & 0.411 & 0.126 & 0.263 & $0.025^{*}$ & 0.202 \\
\hline \multirow[t]{2}{*}{ Age } & -0.041 & 0.026 & 0.122 & -0.05 & 0.084 & 0.006 & -0.099 & -0.07 I & -0.082 & -0.042 & -0.007 & 0.016 & 0.039 \\
\hline & 0.552 & 0.712 & 0.078 & 0.493 & 0.224 & 0.926 & 0.151 & 0.308 & 0.237 & 0.544 & 0.918 & 0.887 & 0.077 \\
\hline Disease type & -0.012 & 0.033 & 0.008 & -0.085 & -0.125 & -0.017 & 0.056 & 0.013 & 0.028 & -0.004 & 0.002 & -0.095 & 0.108 \\
\hline at onset & 0.858 & 0.631 & 0.903 & 0.221 & 0.07 & 0.805 & 0.418 & 0.848 & 0.69 & 0.957 & 0.975 & 0.17 & 0.12 \\
\hline \multirow[t]{2}{*}{ Age at onset } & -0.163 & -0.075 & 0.096 & -0.121 & 0.012 & -0.116 & -0.132 & -0.174 & -0.137 & -0.13 & -0.085 & -0.099 & -0.111 \\
\hline & $0.018^{*}$ & 0.278 & 0.165 & 0.081 & 0.866 & 0.093 & 0.056 & $0.012^{*}$ & $0.047^{*}$ & 0.06 & 0.222 & 0.152 & 0.108 \\
\hline \multirow[t]{2}{*}{ Duration } & 0.322 & 0.251 & 0.053 & 0.241 & 0.202 & 0.257 & 0.164 & 0.288 & 0.144 & 0.2 & 0.225 & 0.288 & 0.353 \\
\hline & $<0.00 I^{*}$ & $<0.00 I^{*}$ & 0.449 & $0.002 *$ & $0.003^{*}$ & $<0.00 I^{*}$ & $0.017^{*}$ & $<0.00 I^{*}$ & $0.038^{*}$ & $0.004^{*}$ & $0.001 *$ & $<0.00 I^{*}$ & $<0.00 I^{*}$ \\
\hline \multirow[t]{2}{*}{ H\&Y stage } & 0.324 & 0.265 & 0.191 & 0.17 & 0.258 & 0.253 & 0.071 & 0.207 & 0.143 & 0.2 & 0.186 & 0.295 & 0.503 \\
\hline & $<0.00 I^{*}$ & $<0.00 I^{*}$ & $0.005^{*}$ & $0.013^{*}$ & $<0.00 I^{*}$ & $<0.00 I^{*}$ & 0.305 & 0.003 & $0.039 *$ & $0.004 *$ & $0.007^{*}$ & $<0.00 I^{*}$ & $<0.001 *$ \\
\hline \multirow[t]{2}{*}{ LD } & 0.296 & 0.217 & 0.125 & 0.146 & 0.221 & 0.173 & 0.086 & 0.204 & 0.193 & 0.167 & 0.17 & 0.236 & 0.408 \\
\hline & $<0.00 I^{*}$ & $0.002^{*}$ & 0.070 & $0.034^{*}$ & $0.001 *$ & $0.012 *$ & 0.212 & $0.003 *$ & $0.005^{*}$ & $0.015^{*}$ & $0.014 *$ & $0.00 I^{*}$ & $<0.00 I^{*}$ \\
\hline \multirow[t]{2}{*}{ DA dose } & 0.082 & 0.099 & -0.027 & -0.046 & 0.024 & -0.086 & 0.105 & 0.058 & 0.085 & 0.15 & 0.038 & -0.62 & 0.078 \\
\hline & 0.234 & 0.152 & 0.702 & 0.507 & 0.726 & 0.215 & 0.128 & 0.404 & 0.22 & $0.03 *$ & $0.58 I$ & 0.371 & 0.263 \\
\hline
\end{tabular}

Notes: Auto contains urinary, sexual, and CV subdomains. NP contains M/A, H/D, and Dep/An subdomains. *Indicates significance. "Sexual dysfunction.

Abbreviations: Auto, autonomic dysfunction; CV, cardiovascular problems; DA dose, dopamine agonist equivalence dose; Dep/An, depression/anxiety; H\&Y, Hoehn and Yahr stage; H/D, hallucination/delusion; LD, levodopa dose; M/A, memory/apathy; Mis, miscellany; NMSQT, nonmotor symptoms questionnaire total score; NP, neuropsychological problems; PDQSI, 39-item Parkinson's Disease Questionnaire summary index; $r$, Spearman's rank correlation coefficient; $U$, urinary. 
Table S3 NMS prevalence and rate of constipation and memory symptoms in other studies

\begin{tabular}{|c|c|c|c|c|c|c|c|}
\hline Study & Location & Subject number & $\begin{array}{l}\text { Age (mean } \pm \\
\text { standard } \\
\text { deviation), years }\end{array}$ & $\begin{array}{l}\text { Prevalence } \\
\text { (\%) }\end{array}$ & $\begin{array}{l}\text { Constipation } \\
\text { rate }(\%)\end{array}$ & $\begin{array}{l}\text { Memory } \\
\text { rate (\%) }\end{array}$ & $\begin{array}{l}\text { Number of } \\
\text { NMS per } \\
\text { patient }\end{array}$ \\
\hline Current study & Taiwan & 210 & $66.1 \pm 9.86$ & 98.6 & 50.95 & 38.1 & 7.77 \\
\hline $\begin{array}{l}\text { Martinez-Martin } \\
\text { et al' }\end{array}$ & International & $\begin{array}{l}525 \text { (Japan }=10, \text { USA }=42, \\
\text { UK }=209, \text { Italy }=\mid 32, \\
\text { Germany }=8 I, \text { Israel }=5 \mid \text { ) }\end{array}$ & $67.66 \pm 10.5$ & 98.4 & 52.48 & 44.85 & 10.25 \\
\hline Chaudhuri et al ${ }^{2}$ & International & $\begin{array}{l}\text { I23 (UK, USA, Italy, } \\
\text { and Germany) }\end{array}$ & $68.1 \pm 10.3$ & 97.6 & 46.7 & 43.9 & 9.48 \\
\hline Gan et $\mathrm{al}^{3}$ & $\begin{array}{l}\text { Shanghai, People's } \\
\text { Republic of China }\end{array}$ & 155 & $71.73 \pm 8.82$ & 98.7 & 64.56 & 65.8 & 8.29 \\
\hline Wu et $\mathrm{al}^{4}$ & $\begin{array}{l}\text { Sichuan, People's } \\
\text { Republic of China }\end{array}$ & 301 & $58.4 \pm 10.9$ & Not given & 29.6 & 58.1 & 8.0 \\
\hline Zhang et $\mathrm{al}^{5}$ & $\begin{array}{l}\text { Nanjing, People's } \\
\text { Republic of China }\end{array}$ & 493 & $65.06 \pm 10.76$ & 98.88 & 57.2 & 68.56 & 10.45 \\
\hline Li et $\left.a\right|^{6}$ & $\begin{array}{l}\text { Beijing, People's } \\
\text { Republic of China }\end{array}$ & 1,225 & $61.48 \pm 10.47$ & 97.6 & 55.3 & 56.1 & 8.72 \\
\hline Cheon et al ${ }^{7}$ & Korea & 74 & $64.9 \pm 8.6$ & 98.6 & 65.8 & 60.8 & 5.2 \\
\hline Tsuboi et $\mathrm{al}^{8}$ & Japan & 53 & $66.1 \pm 11.2$ & Not given & 78.4 & 64.7 & Not given \\
\hline $\begin{array}{l}\text { Rukmini } \\
\text { Mridula et al }\end{array}$ & India & 53 & $56.64 \pm 8.22$ & 100 & 71 & 25 & 8.4 \\
\hline Cosentino et $\mathrm{al}^{10}$ & Peru & 300 & $64.01 \pm 10.25$ & 99.7 & 55.7 & 60.7 & $|2.4|$ \\
\hline Khedr et al" & Egypt & 112 & $61 \pm 12.7$ & 96.4 & 51.79 & 30.36 & 9.52 \\
\hline $\begin{array}{l}\text { Bostantjopoulou } \\
\text { et al }{ }^{12}\end{array}$ & Greece & 164 & $59.5 \pm 9.3$ & 97 & 45.7 & 31.1 & 6.76 \\
\hline Crosiers et $\mathrm{al}^{13}$ & Belgian & 215 & $67.1 \pm 10.4$ & Not given & 38.6 & 37.9 & 9.02 \\
\hline
\end{tabular}

Abbreviation: NMS, nonmotor symptoms.

\section{References}

1. Martinez-Martin P, Schapira AH, Stocchi F, et al. Prevalence of nonmotor symptoms in Parkinson's disease in an international setting; study using nonmotor symptoms questionnaire in 545 patients. Mov Disord. 2007;22(11):1623-1629.

2. Chaudhuri KR, Martinez-Martin P, Schapira AH, et al. International multicenter pilot study of the first comprehensive self-completed nonmotor symptoms questionnaire for Parkinson's disease: the NMSQuest study. Mov Disord. 2006;21(7):916-923.

3. Gan J, Zhou M, Chen W, Liu Z. Non-motor symptoms in Chinese Parkinson's disease patients. J Clin Neurosci. 2014;21(5):751-754.

4. Wu Y, Guo XY, Wei QQ, et al. Non-motor symptoms and quality of life in tremor dominant vs postural instability gait disorder Parkinson's disease patients. Acta Neurol Scand. Epub 2015 Jul 20.

5. Zhang N, Liu W, Ye M, Cohen AD, Zhang Y. The heterogeneity of non-motor symptoms of Parkinson's disease. Neurol Sci. 2015;36(4):577-584.

6. Li DW, Gu Z, Wang C, et al. Non-motor symptoms in Chinese Parkinson's disease patients with and without LRRK2 G2385R and R1628P variants. J Neural Transm. 2015;122(5):661-667.

7. Cheon SM, Ha MS, Park MJ, Kim JW. Nonmotor symptoms of Parkinson's disease: prevalence and awareness of patients and families. Parkinsonism Relat Disord. 2008;14(4):286-290.
8. Tsuboi Y, Yamada T, Chaudhuri RK, et al. Comparison profile of non motor symptoms in Japanese patients with PD with European patients and healthy controls. Extension of the NMSQuest study. Mov Disord. 2006;21(supp115):S648.

9. Rukmini Mridula K, Borgohain R, Jabeen SA, et al. Comparison of frequencies of non motor symptoms in Indian Parkinson's disease patients on medical management versus deep brain stimulation: A case-control study. Iran J Neurol. 2015;14(2):86-93.

10. Cosentino C, Nuñez Y, Torres L. Frequency of non-motor symptoms in Peruvian patients with Parkinson's disease. Arq Neuropsiquiatr. 2013; 71(4):216-219.

11. Khedr EM, El Fetoh NA, Khalifa H, Ahmed MA, El Beh KM. Prevalence of non motor features in a cohort of Parkinson's disease patients. Clin Neurol Neurosurg. 2013;115(6):673-677.

12. Bostantjopoulou S, Katsarou Z, Karakasis C, Peitsidou E, Milioni D, Rossopoulos N. Evaluation of non-motor symptoms in Parkinson's Disease: An underestimated necessity. Hippokratia. 2013;17(3):214-219.

13. Crosiers D, Pickut B, Theuns J, et al. Non-motor symptoms in a FlandersBelgian population of 215 Parkinson's disease patients as assessed by the Non-Motor Symptoms Questionnaire. Am J Neurodegener Dis. 2012;1(2):160-167.
Neuropsychiatric Disease and Treatment

\section{Publish your work in this journal}

Neuropsychiatric Disease and Treatment is an international, peerreviewed journal of clinical therapeutics and pharmacology focusing on concise rapid reporting of clinical or pre-clinical studies on a range of neuropsychiatric and neurological disorders. This journal is indexed on PubMed Central, the 'PsycINFO' database and CAS,

\section{Dovepress}

and is the official journal of The International Neuropsychiatric Association (INA). The manuscript management system is completely online and includes a very quick and fair peer-review system, which is all easy to use. Visit http://www.dovepress.com/testimonials.php to read real quotes from published authors. 